\title{
Improving the gnomonic approach with the gnomonicM R- package to estimate natural mortality throughout different life stages
}

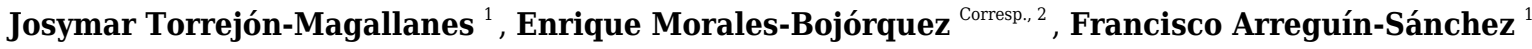 \\ 1 Instituto Politécnico Nacional, Centro Interdisciplinario de Ciencias Marinas, La Paz, Baja California Sur, Mexico \\ 2 Centro de Investigaciones Biológicas del Noroeste, La Paz, Baja California Sur, Mexico \\ Corresponding Author: Enrique Morales-Bojórquez \\ Email address: embojorq@prodigy.net.mx
}

Natural mortality $(M)$ is defined as the rate of loss that occurs in a fish stock due to natural (non-fishing) causes and can be influenced by density-dependent or density-independent factors. Different methods have been used to estimate $M$, one of these is the gnomonic approach. This method estimates $M$ rates by dividing the life cycle of a species into subunits of time that increase as a constant proportion of the time elapsed from birth up to the initiation of each subdivision. In this study, an improved gnomonic approach is proposed to estimate natural mortality throughout different life stages in marine stocks using the gnomonicM package written in $\mathrm{R}$ software. This package was built to require data about (i) the number of gnomonic intervals, (ii) egg stage duration, (iii) longevity, and (iv) fecundity. With this information, it is possible to estimate the duration and natural mortality $\left(M_{i}\right)$ of each gnomonic interval. The gnomonicM package uses a deterministic or stochastic approach, the latter of which assesses variability in $M$ by assuming that the mean lifetime fecundity (MLF) is the main source of uncertainty. Additionally, the gnomonicM package allows the incorporation of auxiliary information related to the observed temporal durations of specific gnomonic intervals, which is useful for calibrating estimates of $M$ vectors. The gnomonicM package, tested via deterministic and stochastic functions, was supported by the reproducibility and verification of the results obtained from different reports, thus guaranteeing its functionality, applicability, and performance in estimating $M$ for different ontogenetic developmental stages. Based on the biological information of Pacific chub mackerel (Scomber japonicus), we presented a new case study to provide a comprehensive guide to data collection to obtain results and explain the details of the application of the gnomonicM package and avoid its misuse. This package could provide an alternative approach for estimating $M$ and provide basic input data for ecological models, allowing the option of using estimates of variable natural mortality across different ages, mainly for life stages affected by fishing. The inputs for the PeerJ reviewing PDF | (2020:10:54574:1:0:NEW 28 Feb 2021) 
gnomonicM packages are composed of numbers, vectors, or characters depending on whether the deterministic or stochastic approach is used, making the package quick, flexible, and easy to use; this allows users to focus on obtaining and interpreting results rather than the calculation process. 
1 Improving the gnomonic approach with the gnomonicM $\mathbf{R}$ 2 package to estimate natural mortality throughout different 3 life stages

4 Josymar Torrejón-Magallanes ${ }^{1}$, Enrique Morales-Bojórquez ${ }^{2}$, Francisco Arreguín-Sánchez ${ }^{1}$

$5{ }^{1}$ Instituto Politécnico Nacional, Centro Interdisciplinario de Ciencias Marinas, La Paz, B.C.S., México

$6 \quad{ }^{2}$ Centro de Investigaciones Biológicas del Noroeste, La Paz, B.C.S., México

7

8 Corresponding Author:

9 Enrique Morales-Bojórquez²

10 Av. Instituto Politécnico Nacional 195, La Paz, Baja California Sur, 23090, México

11 Email address: embojorq@prodigy.net.mx 
12 Abstract

13 Natural mortality $(M)$ is defined as the rate of loss that occurs in a fish stock due to natural (nonfishing) causes and can be influenced by density-dependent or density-independent factors. Different methods have been used to estimate $M$, one of these is the gnomonic approach. This method estimates $M$ rates by dividing the life cycle of a species into subunits of time that increase as a constant proportion of the time elapsed from birth up to the initiation of each subdivision. In this study, an improved gnomonic approach is proposed to estimate natural mortality throughout different life stages in marine stocks using the gnomonicM package written in R software. This package was built to require data about (i) the number of gnomonic intervals, (ii) egg stage duration, (iii) longevity, and (iv) fecundity. With this information, it is possible to estimate the duration and natural mortality $\left(M_{i}\right)$ of each gnomonic interval. The gnomonicM package uses a deterministic or stochastic approach, the latter of which assesses variability in $M$ by assuming that the mean lifetime fecundity $(M L F)$ is the main source of uncertainty. Additionally, the gnomonicM package allows the incorporation of auxiliary information related to the observed temporal durations of specific gnomonic intervals, which is useful for calibrating estimates of $M$ vectors. The gnomonicM package, tested via deterministic and stochastic functions, was supported by the reproducibility and verification of the results obtained from different reports, thus guaranteeing its functionality, applicability, and performance in estimating $M$ for different ontogenetic developmental stages. Based on the biological information of Pacific chub mackerel (Scomber japonicus), we presented a new case study to provide a comprehensive guide to data collection to obtain results and explain the details of the application of the gnomonicM package and avoid its misuse. This package could provide an alternative approach for estimating $M$ and provide basic input data for ecological models, allowing the option of using estimates of variable natural mortality across different ages, mainly for life stages affected by fishing. The inputs for the gnomonicM packages are composed of numbers, vectors, or characters depending on whether the deterministic or stochastic approach is used, making the package quick, flexible, and easy to use; this allows users to focus on obtaining and interpreting results rather than the calculation process.

Keywords: gnomonicM package, Natural mortality, Egg duration, Fecundity, Life span. 


\section{Introduction}

43 Mortality includes all factors that reduce the abundance of a population, and mortality has both

44 natural and non-natural sources. Natural mortality $(M)$ is defined as the rate of loss in a fish stock from natural (non-fishing) causes; natural mortality can be influenced by density-dependent (e.g., predation, cannibalism, disease, size) or density-independent (e.g., oceanographic variables, food availability) factors (Pauly, 1980; Hampton, 2000; Beamish \& Mahnken, 2001). Natural mortality is one of the most influential input parameters in population dynamics and stock assessment models and is usually assumed to be a constant value for all ages and across time. Nevertheless, there is overwhelming evidence that $M$ is likely to vary substantially during the life history of a species, and individuals usually diminish in $M$ from early stages to adults in a population depending on age, length, or weight (Caddy, 1991, 1996; Lorenzen, 1996; Wang \& Haywood, 1999) or over interannual or greater time scales (Zheng, Murphy \& Kruse, 1995; Chu, Chien \& Lee, 2008; Johnson et al., 2014).

Different methods have been used to estimate $M$. The procedures most commonly reported in the literature include direct methods such as tag-recapture and telemetry (Hearn, Pollock \& Brooks, 1998; Pine et al., 2003; Pollock, Jiang \& Hightower, 2004); estimations inside stock assessment or ecosystem models (Walters, Christensen \& Pauly, 1997; Wang \& Liu, 2006; Lee et al., 2011; Crone et al., 2019); and finally metapopulation methods. These last methods are based on empirical equations that incorporate observable life-history parameters for several species (e.g., growth rate, maximum age, sexual maturity) and environmental variables (e.g., mean sea surface temperature) (Alverson \& Carney, 1975; Chen \& Watanabe, 1989; Jensen, 1996; Kenchington, 2014; Pauly, 1980). Among these procedures, metapopulation methods are the most commonly used methods for estimating $M$ since they demand little information; however, the estimates obtained based on these approaches can be biased and are always subject to great uncertainty (Vetter, 1988; Schnute \& Richards, 1995; Zheng, 2003).

Caddy $(1991,1996)$ proposed an approach to calculating an indicative vector of natural death rates at a given age that satisfies population replacement; in this approach, the initial death rate is high, falls off steeply in the early months of life and plateaus later on. The statistical proposal allows the estimation of $M$ from the egg stage to the adult stage for short-lived species following 
a decreasing trend, as is assumed to occur throughout the life history of species. Later, the "gnomonic model" was modified and extended to long-lived species, including the addition of criteria for adjusting the number of gnomonic intervals to the duration of real-life stages, improving the biological sense of the approach, and incorporating variability in fecundity, thus providing estimates of uncertainty in the outputs (Martínez-Aguilar, Arreguín-Sánchez \& Morales-Bojórquez, 2005). These changes increased the versatility and utility of the "gnomonic model" for estimating $M$ in any marine and freshwater spawning species (Giménez-Hurtado, Arreguín-Sánchez \& Lluch-Cota, 2009; Martínez-Aguilar et al., 2010; González-Peláez et al., 2015; Aranceta-Garza et al., 2016; Romero-Gallardo et al., 2018).

According to Caddy $(1991,1996)$, the "gnomonic model" estimates $M$ values with biological and ecological sense, and the statistical procedure is simple and increases the realism in the changes of $M$ that occur during the life cycle of a given species. In this study, the gnomonic approach was improved by modifying some equations and the estimation procedure. Additionally, a package called gnomonicM was written in the $\mathrm{R}$ language, providing a quick and user-friendly tool with which to estimate $M$ throughout the different life stages of marine species. To demonstrate its functionality, the package was applied to the data of previous studies, and the results obtained herein were compared with the results reported in the original studies (Caddy, 1996; MartínezAguilar, Arreguín-Sánchez \& Morales-Bojórquez, 2005) and with those of other published works that used the gnomonic approach. Finally, a detailed new case study focusing on Pacific chub mackerel (Scomber japonicus) was presented, providing a guide for the entire process, from the data compilation to the estimation of $M$ values.

\section{Materials \& Methods}

The gnomonic model constitutes a distinctive approach for estimating natural mortality; its strength is associated with the use of simple biological variables that can be obtained from experimental or documented data. The main advantage of the gnomonic model is its estimation of natural mortality values for the entire life cycle of marine organisms; this is a feature of scientific utility because knowledge about mortality patterns during early life stages (e.g., egg and larvae) is limited and has high uncertainty. In many cases, the mortality of species in these stages can be estimated only under rearing conditions that are often expensive. Thus, a freely 
104 accessible code was developed for obtaining natural mortality estimates based on an improved

105

106

107

108

109

110

111

112

113

114

115

116

117

118

119

120

121

122

123

124

125

126

127

128

129

version, with a new mathematical simplification that allows an increased performance of the gnomonic model in comparison to the original proposal published by Caddy $(1991,1996)$.

\section{Gnomonic interval model and new features}

According to Caddy (1996) and Martínez-Aguilar, Arreguín-Sánchez \& Morales-Bojórquez (2005), the gnomonic method is supported by a negative exponential function in which the independent variable is $\Delta_{i}$, representing the temporal duration of the $i^{\text {th }}$ gnomonic interval; for $i=$ $1,2,3, \ldots, n$, the equation is expressed as follows:

$$
N_{i}=\left\{\begin{array}{l}
M L F * e^{-\left(M_{i} * \Delta_{i}\right)} ; \text { for } i=1 \\
N_{i-1} * e^{-\left(M_{i} * \Delta_{i}\right)} ; \text { for } i>1
\end{array}\right.
$$

where $M_{i}$ is the average value of the natural mortality rate, which integrates the declining death rate through $\Delta_{i}$ and $N_{i}$ are the survivors from the previous $\Delta_{i}$. The initial population for the first gnomonic interval could be assumed as: i) the number of hatching eggs (Caddy 1996), ii) the mean lifetime fecundity ( $M L F)$ (Caddy 1996), or iii) the number of offspring per mating event (Lambert, 2008).

In the gnomonic model, the estimation of $M_{i}$ for each $\Delta_{i}$ requires biological information about (i) the number of developmental stages throughout the life cycle $i \in\{1, \ldots n\}$, (ii) the duration of the first life stage corresponding to the first gnomonic interval $\left(\Delta_{1}=\right.$ egg stage duration), (iii) the $M L F$, and (iv) the lifespan of the species. In biological terms, the $M L F$ is inversely correlated with lifespan, except for specific groups such as semelparous populations (e.g., squids) (Caddy, 1996). As additional information, the duration of the other developmental stages (larvae, juvenile, adults) can be provided. The duration of the second gnomonic interval is defined as $\Delta_{2}$ $=\alpha * t_{2-1}$, where $\alpha$ is a proportionality constant, while the successive gnomonic intervals are calculated as $\Delta_{i}=\left(\alpha * t_{i-1}\right)+t_{i-1}$, where $i \geq 3$ up to the $i^{t h}$ gnomonic interval. $M_{i}$ is proportional to the life stage duration since $\mathrm{G}$ is constant, which was expressed as follows:

$$
M_{i}=\frac{G}{\theta_{i}-\theta_{i-1}}
$$


130 where $G$ is the proportion of the overall natural death rate, being constant for all gnomonic

131 intervals (Caddy, 1996), which is the product of $M_{i} * \Delta_{i}$ and $\theta_{i}=\left(\Delta_{i} / t_{n}\right) / 365$, representing the

132 annual proportional duration of each interval, where $t_{n}$ is the longevity of the species in days

133 (Martínez-Aguilar, Arreguín-Sánchez \& Morales-Bojórquez, 2005).

135 The gnomonic approach is not applicable to marine mammals or sharks; the primary assumption

136 of the gnomonic method is based on the estimation of natural mortality from a negative

137 exponential function, similar to those used to estimate $\mathrm{Z}$ (total mortality). According to this

138 mathematical solution, there must be abundant individuals at time $0\left(\mathrm{~N}_{0}\right)$ to enable the decay in

139 the number of individuals in the population to be estimated. Conversely, whether only one pup or

140 individual is born, the negative exponential function cannot be solved.

Mathematical simplification, uncertainty, and sensitivity

143 In this study, some equations have been modified from Caddy (1996) related to (i) the

144 calculation of the duration of each subsequent gnomonic interval after the egg stage and (ii) the

145 estimation of the constant proportion of the overall natural death rate $(G)$ to improve the model

146 performance during the computational process.

148 The duration of the first gnomonic interval $\left(\Delta_{1}\right)$ is equal to the time elapsed after the moment of

149 hatching $\left(t_{1}\right)$. The durations of the subsequent gnomonic intervals $(i \geq 2)$ are estimated as

150 follows:

151

152

$$
\Delta_{i}=\Delta_{1} * \alpha *(\alpha+1)^{(i-2)}
$$

153

154 where

$155 \Delta_{i}$ is the duration of the gnomonic interval when $i \geq 2$;

$156 \Delta_{1}$ is the duration of first gnomonic interval $t_{1}$;

$157 \alpha$ is the proportionality constant; and

$158 i$ is the $i^{\text {th }}$ gnomonic interval. 
159 According to Caddy (1996) and Martínez-Aguilar, Arreguín-Sánchez \& Morales-Bojórquez 160 (2005), the $\alpha$ and $G$ parameters are estimated by numerical iterations using Newton's algorithm 161 (Neter et al., 1996). The $\alpha$ value is estimated by minimizing the residuals until the sum of the 162 durations of the gnomonic time intervals is equal to $t_{n}$. Unlike the iterative procedure previously

163 164

165

166

167

168

169

170

171

172

173

174

175

176

177

178

179

180

181

182

183

184

185

186 used to estimate $G$, we propose an analytical solution as follows:

$$
N_{i+1}=N_{i} * e^{-G}
$$

This equation could be expressed as follows:

$$
N_{n}=N_{0} *\left(e^{-G}\right)^{n}
$$

According to this equation, $G$ can be estimated based on the total number of gnomonic intervals $i \in\{1, \ldots n\}$ and the value $N_{0}=M L F$. Furthermore, $G$ is chosen so that the number of individuals surviving to the last gnomonic time interval is $N_{n}=2$, following the assumption of stable population replacement with a 1:1 sex ratio; therefore, one female fulfils the requirement for population replacement if the eggs are fertilized (Caddy, 1996). The new equation for $G$ is expressed as follows:

$$
G=-\ln \left[\left(\frac{2}{M L F}\right)^{\frac{1}{n}}\right]
$$

Therefore, only the constant proportionality $(\alpha)$ parameter needs to be estimated. For this purpose, the NEWUOA numerical optimization algorithm (Powell, 2006, 2008) was used, available from the "minqa" package version 1.2.4 of R software (Bates et al., 2014; R Core Team, 2019).

According to Martínez-Aguilar, Arreguín-Sánchez \& Morales-Bojórquez (2005), the variability in $M$ was assessed assuming that $M L F$ was the main source of uncertainty, therefore simulating a total of $j$ samples of $M L F$ with a uniform distribution to determine the uncertainty of $M_{i}$. Then, $M_{i}$ estimates were obtained from $n$ simulations per gnomonic interval, obtaining the mean 
187 natural mortality rate $\left(\bar{M}_{i}\right)$ and the standard deviation $\left(\sigma_{\bar{M} i}\right)$. Another modification in the 188 gnomonicM package is the assessment of the uncertainty via a Monte Carlo simulation, which 189 was improved via the inclusion of three assumed probabilistic density functions for $M L F$ defined 190 as (i) uniform $M L F \sim U\left(M L F_{\text {min, }}, M L F_{\text {max }}\right)$, (ii) normal $M L F \sim N\left(\bar{\mu}_{M L F}, \sigma_{M L F}\right)$, and (iii) triangle $191 M L F \sim$ Triangular $\left(M L F_{\text {min }}, M L F_{\text {max }}, c_{M L F}\right)$, where $M L F_{\text {min }}$ and $M L F_{\text {max }}$ represent the 192 minimum and maximum of the observed $M L F$, respectively; $\bar{\mu}_{M L F}$ and $\sigma_{M L F}$ are the mean and 193 standard deviation of the observed $M L F$, respectively; and $c_{M L F}$ is the mode of the $M L F$ in the 194 triangular distribution. A Monte Carlo simulation must provide a correct stochastic orientation 195 for estimating confidence intervals because the procedure (a) quantifies uncertainty based on 196 statistical distributions derived from data rather than arbitrarily chosen distributions, (b) is 197 unbiased, (c) is accurate, and (d) uses few distributional assumptions (Haddon, 2010;

198 Magnusson, Punt \& Hilborn, 2013). Additionally, in this study, sensitivity can be tested 199 assuming different values in the number of gnomonic intervals, longevity, or egg stage duration 200 in the gnomonicM package. The sensitivity analysis does not require assumptions regarding 201 statistical distributions, such that the user can choose, even arbitrarily, the values of the input 202 parameters (Blackhart, Stanton \& Shimada, 2006; Magnusson, Punt \& Hilborn, 2013).

203

204

205

206

\section{The gnomonicM package}

The source code of the gnomonicM package is freely available from CRAN (https://cran.rproject.org/web/packages/gnomonicM/index.html) or on GitHub at

207

208

209

210

211

212

213 214 215 https://github.com/ejosymart/gnomonicM. This package has been built to provide a user-friendly method for estimating the natural mortality $\left(M_{i}\right)$ and temporal duration of each gnomonic interval, the $\alpha$ parameter of the gnomonic model, and the proportion of the overall natural death rate $(\mathrm{G})$. The main arguments from the gnomonicM package are described in Table 1, and a detailed description is presented in the package manual (https://cran.rproject.org/web/packages/gnomonicM/gnomonicM.pdf). Additional print and plot methods for the deterministic and stochastic approaches are provided to show the results.

\section{Testing the gnomonicM package}


216 For the application of the improved gnomonic approach and to show the functionality of the

217 gnomonicM package, gnomonicM was tested via the deterministic method and by comparing the

218 estimates with the results of two species reported by Caddy (1996); the species had (i) seven

219 gnomonic intervals, (ii) longevity of one year (365 days), (iii) egg stage durations of 2 days, and

220 (iv) $M L F$ values of 200,000 and 135 eggs. Additionally, the methodology was applied to

221 published data that used the gnomonic model, and the estimates were compared with the results

222 provided by the cited authors (see Ramírez-Rodríguez \& Arreguín-Sánchez, 2003; Martínez-

223 Aguilar, Arreguín-Sánchez \& Morales-Bojórquez, 2005; Giménez-Hurtado, Arreguín-Sánchez \&

224 Lluch-Cota, 2009; Martínez-Aguilar et al., 2010; Aranceta-Garza et al., 2016; Romero-Gallardo

225 et al., 2018 for details). This approach allowed the assessment of the application of gnomonicM

226 for different taxa (fish and invertebrates) and life histories (demersal, pelagic, benthic, and short

227 and long-life spans). The gnomonicM package was supported by the reproducibility and

228 verification of the results obtained from different reports, thus guaranteeing its functionality,

229 applicability, and performance in estimating $M$ for different ontogenetic developmental stages.

230

231

The case of Pacific chub mackerel

232 For illustrative purposes with the entire estimation process, Pacific chub mackerel was used as an

233 example. Thus, this section indicates the data requirements and the steps taken to apply the

234

235 gnomonicM package, highlighting its flexibility in parameter estimations, variability in fecundity, the selected probabilistic density function, and the inclusion of auxiliary information on known gnomonic intervals different from the egg stage.

237

238

239

a) Choosing the number of gnomonic intervals. These intervals are defined a priori and should be well represented since they are associated with the ontogenetic development stages, exhibiting realistic subunits of biological time. For Pacific chub mackerel, the biological-ecological criteria indicated the presence of eight gnomonic intervals, which are shown in Table 2 . This means that the intervals should be defined following the gnomonic time framework since they are a key input in the model.

b) Defining the egg stage duration. For Pacific chub mackerel, Hunter and Kimbrell (1980) 
247 information about the fluctuation of the elapsed hatching time as a function of temperature under

248 controlled conditions, ranging from 33 to 117 hours at 23 and $14^{\circ} \mathrm{C}$, respectively.

249

250

c) Including additional information if available (such as the duration of a specific cycle life stage

251 different from the egg stage). Occasionally, some biological information about the duration of a

252 specific life cycle stage is reported, mainly including knowledge of early stages (e.g., the larvae

253 stage) obtained from rearing conditions. If additional information on a known gnomonic interval

254 (life development stage) is provided, then this time duration will not be estimated. For Pacific

255 chub mackerel, no additional information was used in the estimation process.

256

257 d) Including the longevity of the species. The concept of longevity in this study is related to the

258 maximum age that a species could reach, and it is based on growth studies supported by reading

259 otoliths, statoliths and other hard structures, such that the age structure of a population can be

260 known (Beverton, 1987). For Pacific chub mackerel, according to Mendo (1984) and

261 Caramantin-Soriano, Vega-Pérez \& Ñiquen (2008), a longevity of 8 years (2,920 days) was used.

262

263

e) Assigning fecundity values. Fecundity is defined as the number of offspring per mating event

264

(Lambert, 2008), and for the gnomonicM package, fecundity represents the population at time 0;

265

this input can be highly variable depending on several biological, physiological, and

266

environmental conditions (Kjesbu et al., 1998; Zwolinski, Stratoudakis \& Sares, 2001; Lambert,

267

2008). Therefore, the gnomonicM package includes two options: the first is a deterministic

268

approach in which the uncertainty in fecundity is ignored; the second approach involves

269

stochasticity and includes the uncertainty of the fecundity value using a Monte Carlo simulation.

270 For the latter option, the user must assume a probabilistic density function (uniform, normal, or

271

triangular) linked to the fecundity. The procedure provides as outputs the precision of the natural

272

mortality value for each gnomonic interval selected in step a). For Pacific chub mackerel, a

273 uniform probabilistic density function was used based on the fecundity values reported by Peña,

274 Alheit \& Nakama (1986) and Buitrón and Perea (1998) (Table 3).

275

276 f) Assigning an initial value to the $\alpha$ parameter. This step allows a statistical solution when the

277 gnomonic model is optimized. The $\alpha$ parameter has a default initial value equal to 2 . In cases 
278 where the information on this parameter is limited, the user should provide an acceptable $\alpha$ 279 parameter according to the taxonomic group studied, using references previously reported for

280

281

282

283

284

285

286

287

288

289

290

291

292

293

294

295

296

297

298

299

300

301

302

303

304

305

306

307

308

fishes (demersal and pelagic fishes), crustaceans (shrimp), molluscs (cephalopod and clams), or holothurians (sea cucumbers) (see Table S1). In this way, the $\alpha$ parameter represents an initial value that is able to prevent the algorithm from becoming stuck in local minima.

\section{Results}

The gnomonicM package was tested successfully as the results obtained from previous applications were reproducible with the deterministic and stochastic approaches. The results estimated from the gnomonicM package using the deterministic approach and the input data provided by Caddy (1996) for species with high and low fecundity values are shown in Table 4 and Figure 1. For comparative purposes between the values estimated by the gnomonicM package and Caddy (1996), see https://cran.rproject.org/web/packages/gnomonicM/vignettes/gnomonicM.html for details.

The gnomonicM package with the stochastic approach was also successful when applied to other data sources, mainly for shrimp (Farfantepenaeus duorarum), Pacific sardine (Sardinops caeuruleus), and red grouper (Epinephelus morio); for these species, differences were not found among the parameters $(\mathrm{G}, \alpha)$, durations of gnomonic intervals, or natural mortality values (Table S1: A, B, C). Conversely, for jumbo squid (Dosidicus gigas), white shrimp (Litopenaeus vannamei), and sea cucumber (Isostichopus badionotus), differences were found among the parameters, durations of gnomonic intervals, and natural mortality values estimated from the gnomonicM package. With these differences, although they varied within similar numerical scales, the results were not completely reproducible. The reasons for these difference could be explained by three sources of variability: a) the use of additional information not provided in the reports, b) the statistical routine used for generating random numbers related to the $M L F$, or c) possibly some parameters that could have been held constant during the numerical optimization process. The differences in natural mortality could be classified as slight for jumbo squid and white shrimp, while that for sea cucumber was greater (Table S1: D, E, F). Specifically, for Isostichopus badionatus, the natural mortality estimates reported by Romero-Gallardo et al. (2018) did not include the egg stage duration as the first gnomonic interval; instead, the authors used the duration to early auricularia (planktonic larvae), and this substitution represents a

Peer) reviewing PDF | (2020:10:54574:1:0:NEW 28 Feb 2021) 
309

310

311

312

313

314

315

316

317

318

319

320

321

322

323

324

325

326

327

328

329

330

331

332

333

334

335

336

337

338

misspecification in the input data, indicating methodological infringement on the gnomonic method that is easily avoidable using the gnomonicM package.

For the case of Pacific chub mackerel, the results based on the stochastic method are presented in Table 5. When the temporal duration of the egg stage was varied, the estimated durations of the following gnomonic intervals in comparison with their observed durations (Table 2) did not show significant differences (Kruskal-Wallis, $\mathrm{p}=0.94$ ). Comparatively, the estimates based on an egg duration of 56 hours (2.33 days, $\alpha=1.77)$ were the most similar to the observed duration values. The choice of the egg stage duration influenced the estimates of $\bar{M}$, showing significant differences when comparing $\bar{M}$ values for the same gnomonic intervals (ANOVA, $\mathrm{p}<0.01$ ). The estimation of $\bar{M}_{i}$ and the standard deviation $\sigma_{i}$ decreased with age independently of the different scenarios (different egg stage durations and $M L F$ values). The values of $\bar{M}_{i}$ for the early stages, from egg to larvae, were relatively high $\left(344.44 \mathrm{yr}^{-1}-23.87 \mathrm{yr}^{-1}\right)$, while the $\bar{M}_{i}$ values for adults ( $\left.\bar{M}_{7}=0.62 \mathrm{yr}^{-1}-0.73 \mathrm{yr}^{-1}\right)$ and late adults $\left(\bar{M}_{8}=0.22 \mathrm{yr}^{-1}-0.27 \mathrm{yr}^{-1}\right)$ showed low variability and the lowest values (Figure 2, Table 5). The parameter $\alpha$ was associated with the durations of life-history stages, showing an inverse relation with the egg stage duration, and it was independent of the $M L F$; the $G$ parameter had a constant value under three different egg stage duration scenarios, and its magnitude increased with greater $M L F$ values (Table 5).

\section{Discussion}

\section{The gnomonicM package and other methods}

Compared to the method employed by Caddy (1996), the gnomonicM package uses simplified algebra, increasing its parsimony. The original gnomonic model proposed estimations of the $\alpha$ and $\mathrm{G}$ parameters in two independent numerical optimizations, while the gnomonicM package used an algebraic estimator for $\mathrm{G}$ and an analytic estimator for $\alpha$ supported by the NEWUOA numerical optimization algorithm (Powell, 2006, 2008). Another feature of the gnomonicM package is the biological and ecological sense linking the gnomonic concept to the life cycle of any given species, expressed as the development of the ontogenetic stages (Martínez-Aguilar, Arreguín-Sánchez \& Morales-Bojórquez, 2005). Moreover, the gnomonicM package allows the 
339 incorporation of auxiliary information for specific gnomonic intervals related to their observed

340 time durations; this contribution is useful for calibrating estimates of $M$ vectors. Furthermore, the

341 gnomonicM package provides confidence intervals (CI 95\%) of natural mortality for each

342 estimated gnomonic interval, assuming that the main source of uncertainty is the mean lifetime

343 fecundity. The latter can be assumed to be non-informative (i.e., with a uniform distribution) or

344 informative (i.e., with normal and triangular distributions). The choice of the probabilistic

345 density function will affect the natural mortality estimates; however, the uncertainty regarding

346 fecundity must not be limited to only non-informative distribution (Martínez-Aguilar, Arreguín-

347 Sánchez \& Morales-Bojórquez, 2005).

348

349 According to Quinn \& Deriso (1999) and Kenchington (2014), the natural mortality estimation

350 methods require different input data and variables, and some of these data could be difficult to

351 obtain because they are usually associated with extensive time series (i.e., length-frequency

352 analysis and some stock assessment models); others, such as tag-recapture and telemetry in

353 oceans, are usually expensive and sometimes provide imprecise estimates (Hearn, Pollock \&

354 Brooks, 1998; Pine et al., 2003; Pollock, Jiang \& Hightower, 2004), while some are supported by

355 knowledge of the age structure of a population and its growth parameters (in methods based on

356 the life history and maximum observed age of a species). These meta-analysis estimators are

357 biological generalizations that use multiple regression analysis with independent variables, such

358 as growth and environmental variables, whose application is limited to certain marine taxa.

359 Regarding the uncertainty, a common feature of the above methods is the absence of an

360 uncertainty calculation, expressed as a confidence interval (Kenchington, 2014). Although the

361 gnomonicM package requires specific biological data, it provides estimates of $M$ for the entire

362 life cycles of marine organisms; estimations are commonly scarce for egg and larval stages, and

363 the gnomonicM package also includes an analysis of uncertainty represented by the confidence

364 intervals of $M$. Furthermore, the sensitivity of the estimated $M$ values can be tested by varying

365 the duration of the egg stage, since this stage is a critical input data for the gnomonic model,

366 affecting the estimated $M$ values mainly at the early stages of development. Finally, the

367 gnomonicM package provides estimations of $M$ via numerical optimization in comparison to

368 deterministic estimators (see Kenchington, 2014). 


\section{The Pacific chub mackerel case and details about gnomonicM applications}

371 The aim of presenting a new case study was to provide a comprehensive guide for data collection

372 and obtaining results and to explain the details of the application of the gnomonicM package to

373 avoid its misuse. Based on the gnomonic approach, biological information regarding the life

374 cycle of a given species must include the temporal duration of the egg stage, longevity, and

375 fecundity. For Pacific chub mackerel, the biological data were collected from several sources

376 (Table 1). At this step, the main challenge was the different criteria among authors focusing on

377 the definitions of biological stages and their durations. For example, in the larval stage, it is

378 common to find subclassifications, referred to as pre-larvae, early larvae, larvae, yolk-sac larvae,

379 and post-larvae stages; for some species, there are even subcategories defined as I or II (e.g.,

380 Martínez-Aguilar, Arreguín-Sánchez \& Morales-Bojórquez, 2005; González-Peláez et al., 2015).

381 Moreover, contrasting results regarding the development stage can be documented from rearing

382 conditions or field observations. The solution to this problem can be addressed by the well-

383 defined concept of the gnomonic interval (Caddy, 1991, 1996). This means that some stages

384 could be considered individually or grouped to make up a particular gnomonic interval

385 considering the biological and ecological characteristics of the interval, with the purpose that

386 each successive gnomonic interval is greater than the previous interval in its duration. If this

387 condition is not satisfied, then the results will be biased due to the misspecification of data.

388 Another cause can be related to the lack of specific biological data for the species studied;

389 therefore, some generalizations could be assumed, such as, for example, using a characteristic

390 (e.g., duration) of the development stages of other members of the same taxonomic genus, even

391 from different geographical regions.

392

393 Once the data have been collected, they are introduced directly as input arguments (see Table 1).

394 These inputs are simply composed of numbers, vectors, or characters depending on the approach

395 used, either deterministic or stochastic, providing a quick, flexible, and user-friendly tool with

396 characteristics that a software package should have (Wilson et al., 2017). This approach allows

397 users to focus on obtaining and interpreting results rather than the calculation process. Therefore,

398 when the deterministic approach is selected via the gnomonic function, the input data must be

399 organized as follows:

400

$401 \mathrm{x}<-$ gnomonic(nInterval $=8$, 
402

403

404

405

406

407

408

409

410

411

412

413

414

415

416

417

418

419

420

421

422

423

424

425

426

427

428

429

430

431

432

433

434

435

436

437

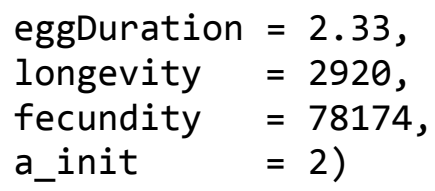

In the case of the stochastic approach via the gnomonicStochastic function, the input data must be organized as follows:

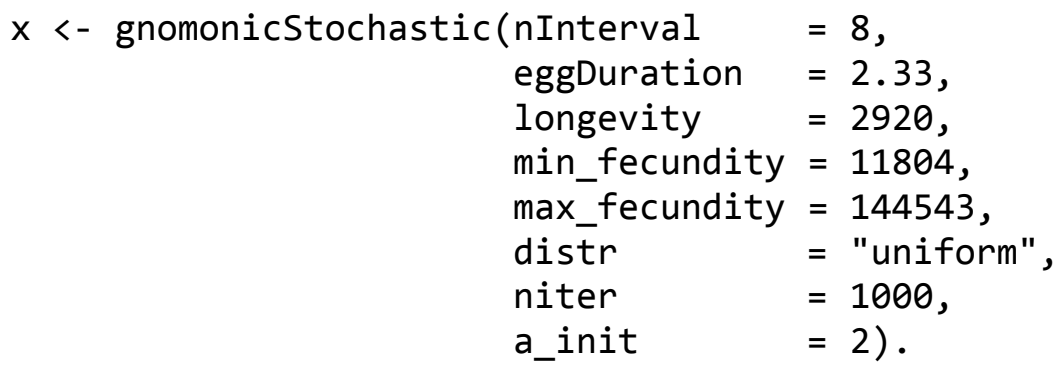

For any option selected previously, the numerical outputs can be obtained from print $(x)$, and the graphic representation is available for the user from plot $(x)$.

The scenarios described above represent a sensitivity analysis available from the gnomonicM package; the rationale is supported by the role of the environmental variability influencing the fecundity and the egg stage duration, both of which have impacts on the natural mortality of $S$. japonicus. The sensitivity analysis must be based on biological and ecological knowledge of the analysed species, such that the scenarios estimated from this approach can be plausible. In this way, the use of the gnomonicM package requires clear criteria for estimating the number of scenarios useful for each case. In this study, we tested scenarios based on the duration of the egg stage and MLF. We chose the scenario of 56 hours (2.33 days) as the "best" scenario because the estimations of the durations of the gnomonic intervals obtained under this scenario were very similar to the observed values (Tables 2 and 5). Additionally, these durations increased over the life cycle following the gnomonic time concept (Caddy, 1996). The $M$ values for different stages were similar to the reported values for the egg and larvae stages (Watanabe, 1970; Ware \& Lambert, 1985), and the differences were presented for the adult phases due to the method used, such as catch curve analysis, stock assessment and empirical equations (Tables 5 and 6).

The natural mortality values estimated from the gnomonicM package for Pacific chub mackerel showed an adequate biological trajectory through the different ontogenetic developmental stages, 
438 with the highest values observed during the early development stages, indicating that the

439 gnomonic times selected for this species were adequately grouped. Regarding ecological theory,

440 the early stages of Pacific chub mackerel are exposed to high rates of predation by planktonic

441 organisms and fish. This species has a variety of predators depending on the phase of

442 development. The main predators at different sizes of Pacific chub mackerel, including juveniles, 443 are hake Merluccius gayi and the eastern bonito Sarda chilensis (Ojeda \& Jaksic, 1979; Fuentes, 444 Antonietti \& Muck, 1989). Cannibalism is another source that increases natural mortality, and 445 several studies on this species have shown evidence of cannibalism in eggs and individuals 8$446 \mathrm{~mm}$ and larger, particularly in spawning grounds. It is important to mention that if the egg stage 447 duration is long or if the transition from egg to larvae is slow, the organism may be subject to 448 predation mortality for longer periods, resulting in high natural mortality (Pitcher \& Hart, 1982).

Finally, the improved approach and the use of the gnomonicM package adequately represented the biological developmental stages of the species assessed in this study over its life cycle. Additionally, estimates of $M$ produced by the gnomonicM package may provide basic input data to ecological models, enabling them to use estimates of variable $M$ across different ages groups, mainly for the life stages affected by fishing.

\section{Conclusions}

457 The improved gnomonic approach implemented in the gnomomicM $\mathrm{R}$ package provides a method for estimating natural mortality $(M)$ throughout the different life stages of aquatic species, fish, and invertebrates. The data required for gnomonicM must include, at least, the number of gnomonic intervals, egg stage duration, longevity, and fecundity. These input data have intrinsic uncertainty: a) fecundity is associated with high levels of uncertainty because the mean lifetime fecundity depends on specific studies on reproductive biology and is influenced by environmental variability, density-dependent effects, and biological features of the stock; b) the egg stage duration is commonly taken from rearing studies under controlled conditions (e.g., temperature, salinity) as the duration can rarely be obtained from field data; c) the longevity depends on the maximum age identified from the age structure for the population studied; thus, the longevity requires specific studies of hard structures (e.g., otoliths, spines, vertebrae); the number of gnomonic intervals must be determined, these must be established using biological 
469 criteria when using the gnomonicM package, such that the ontogenetic development stages can

470 be useful in reducing the uncertainty in the number of intervals selected. The number of

471 gnomonic intervals provided must be such that the duration of each successive gnomonic interval

472 is greater than the previous one $\left(\Delta_{i}\right)$, which implies that several development stages can be

473 grouped to satisfy this assumption. Specifically, the last gnomonic interval would group the

474 ontogenetic stage of adult individuals; this criterion enables this interval to be highly flexible.

475 For annual-lived species several months could constitute a group (the lifetime for adults), while

476 for long-lived species several years could be grouped, these being linked to the age structure of

477 the adult population. Additionally, gnomonicM allows the incorporation of auxiliary information

478 related to the observed temporal duration of specific gnomonic intervals, which is useful for

479 calibrating estimates of $M$ vectors. Finally, the additional plot() and print() functions are

480 provided for numerical and graphical representations, making the package quick, flexible, and

481 easy to use and allowing users to focus on obtaining and interpreting results rather than on the

482 calculation process.

483

484 Acknowledgements

485 Josymar Torrejón-Magallanes wishes to thank Miguel Ñiquen and Marilú Bouchon for the

486 biological information and discussion about the life history of Pacific chub mackerel and Enrique

487 Ramos for mathematical support. FAS thanks support offered by the Instituto Politécnico

488 Nacional through COFAA and EDI programs. We sincerely wish to thank the editor and two

489 anonymous reviewers for their thoughtful comments and suggestions that improved both the

490 quality of this manuscript and the gnomonicM package. 
491

492

493

494

495

496

497

498

499

500

501

502

503

504

505

506

507

508

509

510

511

512

513

514

515

516

517

518

519

520

521

522

523

524

525

526

527

528

529

\section{References}

Alverson DL, Carney MJ. 1975. A graphic review of the growth and decay of population cohorts. ICES Journal of Marine Science 36:133-143. DOI: 10.1093/icesjms/36.2.133.

Aranceta-Garza F, Arreguín-Sánchez F, Ponce-Díaz G, Seijo JC. 2016. Natural mortality of three commercial penaeid shrimps (Litopenaeus vannamei, L. stylirostris and Farfantepenaeus californiensis) of the Gulf of California using gnomonic time divisions. Scientia Marina 80:199-206. DOI: 10.3989/scimar.04326.29A.

Bates D, Mullen K, Nash J, Varadhan R. 2014. minqa: Derivative-free optimization algorithms by quadratic approximation. $\mathrm{R}$ package version 1.2.4.

Beamish RJ, Mahnken C. 2001. A critical size and period hypothesis to explain natural regulation of salmon abundance and the linkage to climate and climate change. Progress in Oceanography 49:423-437. DOI: 10.1016/S0079-6611(01)00034-9.

Beverton RJ. 1987. Longevity in fish: some ecological and evolutionary considerations. In: Evolution of Longevity in Animals. Springer, Boston, MA, 161-185. DOI: 10.1007/978-14613-1939-9_12.

Blackhart K, Stanton DG, Shimada AM. 2006. NOAA fisheries glossary. NOAA Technical Memorandum NMFS-F/SPO-69, MD: NOAA:61.

Buitrón B, Perea A. 1998. Estimación de la fecundidad parcial de la caballa (Scomber japonicus peruanus) a inicios de otoño 1998. Crucero BIC Humbodlt 9803-05 de Tumbes a Tacna. Instituto del Mar del Perú 135:143-146.

Caddy JF. 1991. Death rates and time intervals: is there an alternative to the constant natural mortality axiom? Reviews in Fish Biology and Fisheries 1:109-138. DOI: 10.1007/BF00157581.

Caddy JF. 1996. Modelling natural mortality with age in short-lived invertebrate populations: definition of a strategy of gnomonic time division. Aquatic Living Resources 9:197-207. DOI: $10.1051 /$ alr:1996023.

Caramantin-Soriano H, Vega-Pérez LA, Ñiquen M. 2008. Growth parameters and mortality rate of the Scomber japonicus peruanus (Jordán \& Hubb, 1925) along the Peruvian coast, South Pacific. Brazilian Journal of Oceanography 56:201-210. DOI: 10.1590/S167987592008000300005.

Chen S, Watanabe S. 1989. Age Dependence of Natural Mortality Coefficient in Fish Population Dynamics. Nippon Suisan Gakkaishi (Japanese Edition) 55:205-208. DOI: 10.2331/suisan.55.205.

Chu CYC, Chien HK, Lee RD. 2008. Explaining the optimality of U-shaped age-specific mortality. Theoretical Population Biology 73:171-180. DOI: 10.1016/j.tpb.2007.11.005.

Crone PR, Hill KT, Zwolinski JP, Kinney MJ. 2019. Pacific mackerel (Scomber japonicus) stock assessment for U.S. management in the 2019-20 and 2020-21 fishing years. Portland, Pacific Fishery Management Council. 
530

531

532

533

534

535

536

537

538

539

540

541

542

543

544

545

546

547

548

549

550

551

552

553

554

555

556

557

558

559

560

561

562

563

564

565

566

567

568

Fuentes H, Antonietti E, Muck P. 1989. Alimentación de la merluza (Merluccius gayi peruanus) de la zona de Paita. In: Memorias del simposio internacional de los recursos vivos y las pesquerías en el Pacífico Sudeste. 9-13.

Giménez-Hurtado E, Arreguín-Sánchez F, Lluch-Cota SE. 2009. Natural mortality rates during life history stages of the red grouper on Campeche Bank, Mexico. North American Journal of Fisheries Management 29:216-222. DOI: 10.1577/M06-041.1.

González-Peláez SS, Morales-Bojórquez E, Lluch-Cota DB, Bautista-Romero JJ. 2015. Application of a gnomonic model to estimate the life span and natural mortality in Panopea globosa. Journal of Shellfish Research 34:113-118. DOI: 10.2983/035.034.0114.

Haddon M. 2010. Modelling and quantitative methods in fisheries. CRC press.

Hampton J. 2000. Natural mortality rates in tropical tunas: size really does matter. Canadian Journal of Fisheries and Aquatic Sciences 57:1002-1010. DOI: 10.1139/f99-287.

Hearn WS, Pollock KH, Brooks EN. 1998. Pre- and post-season tagging models: Estimation of reporting rate and fishing and natural mortality rates. Canadian Journal of Fisheries and Aquatic Sciences 55:199-205. DOI: 10.1139/f97-243.

Hunter J, Kimbrell C. 1980. Early Life History of Pacicfic Mackerel, Scomber japonicus. Fishery Bulletin 78:89-101.

Jensen AL. 1996. Beverton and Holt life history invariants result from optimal trade-off of reproduction and survival. Canadian Journal of Fisheries and Aquatic Sciences 53:820822. DOI: $10.1139 / \mathrm{f95}-233$.

Johnson KF, Monnahan CC, McGilliard CR, Vert-Pre KA, Anderson SC, Cunningham CJ, Hurtado-Ferro F, Licandeo RR, Muradian ML, Ono K, Szuwalski CS, Valero JL, Whitten AR, Punt AE. 2014. Time-varying natural mortality in fisheries stock assessment models: Identifying a default approach. In: ICES Journal of Marine Science. Oxford University Press, 137-150. DOI: 10.1093/icesjms/fsu055.

Kenchington TJ. 2014. Natural mortality estimators for information-limited fisheries. Fish and Fisheries 15:533-562. DOI: 10.1111/faf.12027.

Kjesbu OS, Witthames PR, Solemdal P, Greer Walker M. 1998. Temporal variations in the fecundity of arcto-Norwegian cod (Gadus morhua) in response to natural changes in food and temperature. Journal of Sea Research 40:303-321. DOI: 10.1016/S13851101(98)00029-X.

Lambert Y. 2008. Why should we closely monitor fecundity in marine fish populations? Journal of Northwest Atlantic Fishery Science 41:93-106. DOI: 10.2960/J.v41.m628.

Lee HH, Maunder MN, Piner KR, Methot RD. 2011. Estimating natural mortality within a fisheries stock assessment model: An evaluation using simulation analysis based on twelve stock assessments. Fisheries Research 109:89-94. DOI: 10.1016/j.fishres.2011.01.021.

Lorenzen K. 1996. The relationship between body weight and natural mortality in juvenile and adult fish: A comparison of natural ecosystems and aquaculture. Journal of Fish Biology 49:627-647. DOI: 10.1006/jfbi.1996.0192.

Peer) reviewing PDF | (2020:10:54574:1:0:NEW 28 Feb 2021) 
569

570

571

572

573

574

575

576

577

578

579

580

581

582

583

584

585

586

587

588

589

590

591

592

593

594

595

596

597

598

599

600

601

602

603

604

605

606

Magnusson A, Punt AE, Hilborn R. 2013. Measuring uncertainty in fisheries stock assessment: The delta method, bootstrap, and MCMC. Fish and Fisheries 14:325-342. DOI: 10.1111/j.1467-2979.2012.00473.x.

Martínez-Aguilar S, Arreguín-Sánchez F, Morales-Bojórquez E. 2005. Natural mortality and life history stage duration of Pacific sardine (Sardinops caeruleus) based on gnomonic time divisions. Fisheries Research 71:103-114. DOI: 10.1016/j.fishres.2004.04.008.

Martínez-Aguilar S, Díaz Uribe JG, De Anda-Montañez JA, Cisneros-Mata MÁ. 2010. Natural mortality and life history stage duration for the jumbo squid (Dosidicus gigas) in the Gulf of California, Mexico, using the gnomonic time division. Ciencia Pesquera 18:31-42.

Mendo J. 1984. Edad, crecimiento y algunos aspectos reproductivos y alimentarios de la caballa (Scomber japonicus peruanus). Boletín Instituto del Mar del Perú 8:101-156.

Neter J, Kutner M, Nachtsheim C, Wasserman W. 1996. Applied linear statistical models. Boston.

Ojeda FP, Jaksic F. 1979. Utilización diferencial de recursos alimenticios por dos poblaciones simpatricas de Scomber japonicus peruanus y Sarda sarda chiliensis en el Norte de Chile. Medio Ambiente 4:19-23.

Pauly D. 1980. On the interrelationships between natural mortality, growth parameters, and mean environmental temperature in 175 fish stocks. ICES Journal of Marine Science 39:175-192. DOI: 10.1093/icesjms/39.2.175.

Peña N, Alheit J, Nakama ME. 1986. Fecundidad parcial de Caballa del Perú (Scomber japonicus peruanus). Instituto del Mar del Perú 10:94-104.

Pine WE, Pollock KH, Hightower JE, Kwak TJ, Rice JA. 2003. A review of tagging methods for estimating fish population size and components of mortality. Fisheries 28:10-23. DOI: 10.1577/1548-8446(2003)28[10:arotmf]2.0.co;2.

Pitcher T, Hart P. 1982. Fisheries ecology. London: Chapman \& Hall.

Pollock KH, Jiang H, Hightower JE. 2004. Combining telemetry and fisheries tagging models to estimate fishing and natural mortality rates. Transactions of the American Fisheries Society 133:639-648. DOI: 10.1577/t03-029.1.

Powell MJD. 2006. The NEWUOA software for unconstrained optimization without derivatives. In: Large-Scale Nonlinear Optimization. Springer, Boston, MA, 255-297. DOI: 10.1007/0387-30065-1_16.

Powell MJD. 2008. Developments of NEWUOA for minimization without derivatives. IMA Journal of Numerical Analysis 28:649-664. DOI: 10.1093/imanum/drm047.

Quinn TJ, Deriso RB. 1999. Quantitative Fish Dynamics. New York: Oxford University Press.

R Core Team. 2019. R: A language and environment for statistical computing.

Ramírez-Rodríguez M, Arreguín-Sánchez F. 2003. Life history stage duration and natural mortality for the pink shrimp Farfantepenaeus duorarum (Burkenroad, 1939) in the southern Gulf of Mexico, using the gnomonic model for time division. Fisheries Research 
607

608

609

610

611

612

613

614

615

616

617

618

619

620

621

622

623

624

625

626

627

628

629

630

631

632

633

634

635

636

637

638

639

640

641

60:45-51. DOI: 10.1016/S0165-7836(02)00064-4.

Romero-Gallardo S, Velázquez-Abunader I, Alberto López-Rocha J, Garza-Gisholt E. 2018. Natural mortality estimates throughout the life history of the sea cucumber Isostichopus badionotus (Holothuroidea: Aspidochirotida). PeerJ 6. DOI: 10.7717/peerj.5235.

Schnute JT, Richards LJ. 1995. The influence of error on population estimates from catch-age models. Canadian Journal of Fisheries and Aquatic Sciences 52:2063-2077. DOI: 10.1139/f95-800.

Vetter EF. 1988. Estimation of natural mortality in fish stocks: a review. Fishery Bulletin 86:2543.

Walters C, Christensen V, Pauly D. 1997. Structuring dynamic models of exploited ecosystems from trophic mass-balance assessments. Reviews in Fish Biology and Fisheries 7:139-172. DOI: $10.1023 / \mathrm{A}: 1018479526149$.

Wang YG, Haywood MDE. 1999. Size-dependent natural mortality of juvenile banana prawns Penaeus merguiensis in the Gulf of Carpentaria, Australia. Marine and Freshwater Research 50:313-317. DOI: 10.1071/MF97229.

Wang Y, Liu Q. 2006. Estimation of natural mortality using statistical analysis of fisheries catchat-age data. Fisheries Research 78:342-351. DOI: 10.1016/j.fishres.2005.11.020.

Ware DM, Lambert TC. 1985. Early life history of Atlantic mackerel (Scomber scombrus) in the southern Gulf of St. Lawrence. Canadian Journal of Fisheries and Aquatic Sciences 42:577-592. DOI: 10.1139/f85-075.

Watanabe T. 1970. Morphology and ecology of early stages of life in Japanese common mackerel, Scomber japonicus Houttuyn, with special reference to fluctuation of population. Bulletin of the Tokai Regional Fisheries Research Laboratory 62:1-283.

Wilson G, Bryan J, Cranston K, Kitzes J, Nederbragt L, Teal TK. 2017. Good enough practices in scientific computing. PLoS Computational Biology 13:e1005510. DOI: 10.1371/journal.pcbi.1005510.

Zheng J. 2003. Uncertainties of natural mortality estimates for eastern Bering Sea snow crab, Chionoecetes opilio. Fisheries Research 65:411-425. DOI: 10.1016/j.fishres.2003.09.029.

Zheng J, Murphy MC, Kruse GH. 1995. A length-based population model and stock-recruitment relationships for red king crab, Paralithodes camtschaticus, in Bristol Bay, Alaska. Canadian Journal of Fisheries and Aquatic Sciences 52:1229-1246. DOI: 10.1139/f95-120.

Zwolinski J, Stratoudakis Y, Sares E. 2001. Intra-annual variation in the batch fecundity of sardine off Portugal. Journal of Fish Biology 58:1633-1645. DOI: 10.1111/j.10958649.2001.tb02318.x. 
Figure 1

Estimation of natural mortality $(M)$ by each gnomonic interval based on data provided in Caddy (1996).

(A) Species with higher MLF $=200,000$ eggs. (B) Species with low MLF $=135$ eggs. Each data point indicates the value for a particular gnomonic interval. The black line represents the rolling mean.
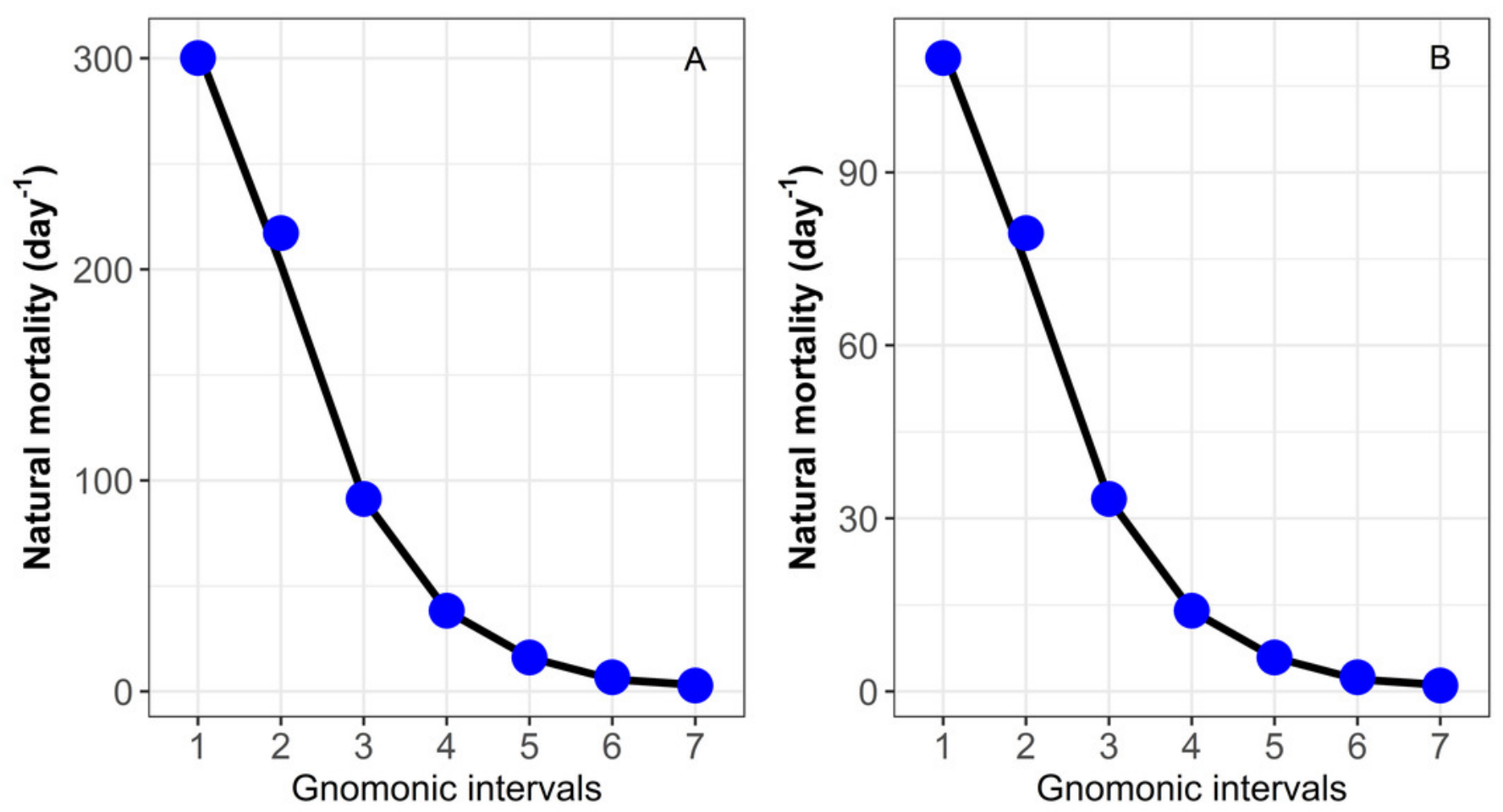
Figure 2

Natural mortality $(M)$ vector estimated for Pacific chub mackerel (Scomber japonicus).

Columns represent a species with higher MLF $=78,174$ and lower $M L F=28,978$ values. Rows represents a different egg stage duration: $33 \mathrm{~h}, 56 \mathrm{~h}, 117 \mathrm{~h}$, respectively. 

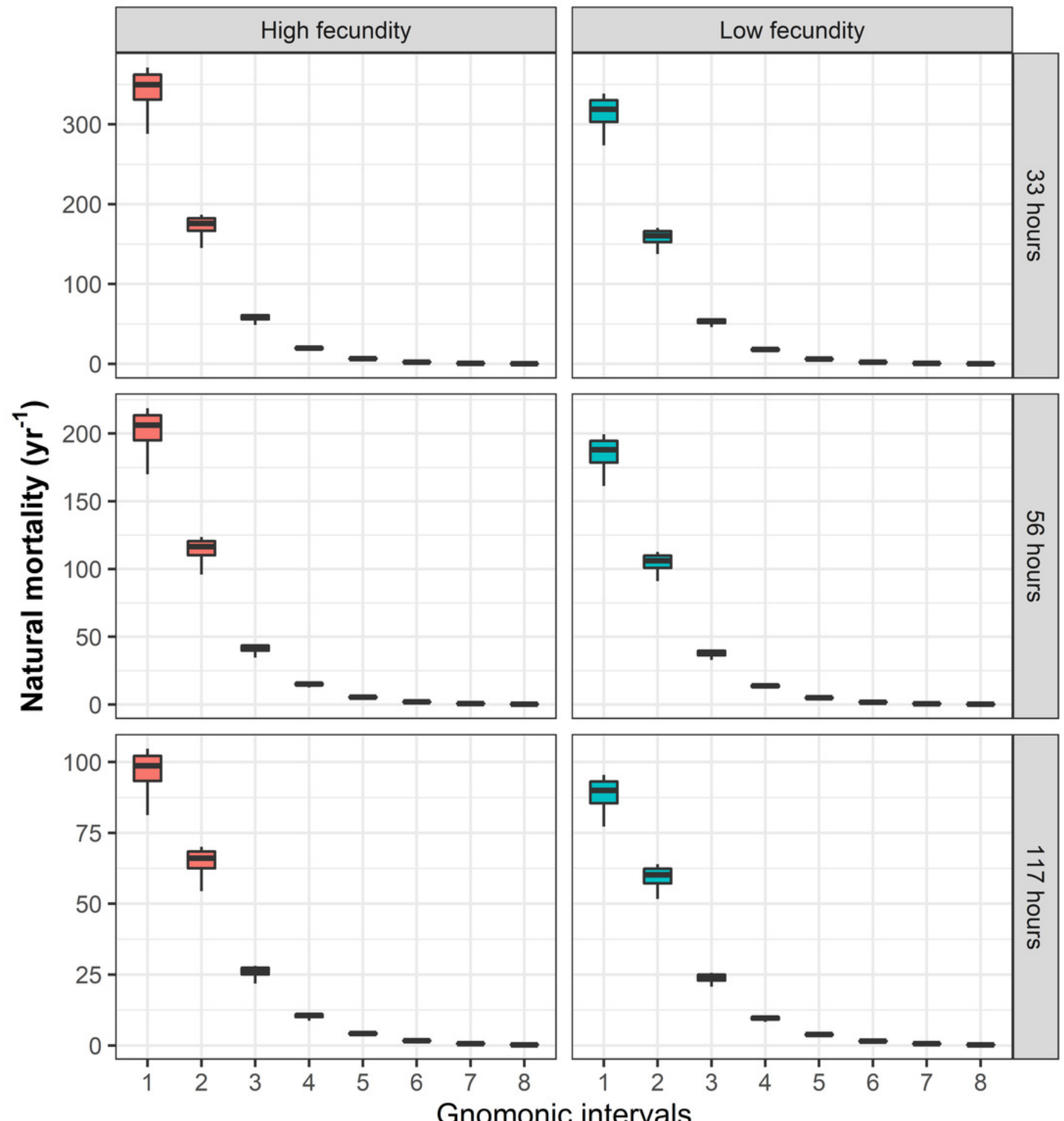
Table $\mathbf{1}$ (on next page)

Input arguments for the gnomonicM package. 


\begin{tabular}{|c|c|c|c|c|}
\hline Argument & Type & Description & Default & Required \\
\hline nInterval & Numeric & $\begin{array}{l}\text { An integer specifying the number of gnomonic } \\
\text { intervals }\end{array}$ & - & Yes \\
\hline eggDuration & Numeric & $\begin{array}{l}\text { A single numeric value with the egg stage } \\
\text { (first gnomonic interval) duration in days. }\end{array}$ & - & Yes \\
\hline addInfo & $\begin{array}{l}\text { Numeric } \\
\text { vector }\end{array}$ & $\begin{array}{l}\text { A numeric vector with additional information } \\
\text { (if available) related to the observed duration } \\
\text { of the gnomonic intervals different from the } \\
\text { egg stage. }\end{array}$ & NULL & No \\
\hline longevity & Numeric & $\begin{array}{l}\text { An integer indicating the lifespan of the } \\
\text { species specified in days. }\end{array}$ & - & Yes \\
\hline fecundity & Numeric & $\begin{array}{l}\text { A numeric value indicating the mean lifetime } \\
\text { fecundity expressed as the number of eggs } \\
\text { produced for a female. If a "normal" or } \\
\text { "triangular" distribution is assumed, this value } \\
\text { will be interpreted as the mean or the mode, } \\
\text { respectively. }\end{array}$ & NULL & Yes \\
\hline distr & $\begin{array}{l}\text { Character } \\
\text { string }\end{array}$ & $\begin{array}{l}\text { Name of the probabilistic density function to } \\
\text { be applied, which must be defined as: } \\
\text { "uniform", "normal", "triangle". }\end{array}$ & "uniform" & Yes \\
\hline sd_fecundity & Numeric & $\begin{array}{l}\text { A numeric value indicating the standard } \\
\text { deviation of fecundity if a "normal" } \\
\text { distribution is assumed. }\end{array}$ & NULL & Yes \\
\hline min_fecundity & Numeric & $\begin{array}{l}\text { A numeric value indicating the minimum } \\
\text { range of fecundity if a "uniform" or "triangle" } \\
\text { distribution is assumed. }\end{array}$ & NULL & Yes \\
\hline max_fecundity & Numeric & $\begin{array}{l}\text { A numeric value indicating the minimum } \\
\text { range of fecundity if a "uniform" or "triangle" } \\
\text { distribution is assumed. }\end{array}$ & NULL & Yes \\
\hline a_init & Numeric & $\begin{array}{l}\text { A numeric value indicating the initial }(\alpha) \\
\text { parameter related to the proportionality } \\
\text { constant which will be numerically optimized. }\end{array}$ & 2 & Yes \\
\hline niter & Numeric & $\begin{array}{l}\text { An integer value representing the number of } \\
\text { iterations. }\end{array}$ & 999 & No \\
\hline seed & Numeric & $\begin{array}{l}\text { A single value interpreted as an integer } \\
\text { ensures that the same (pseudo) random } \\
\text { numbers will be generated each time the script } \\
\text { is executed. }\end{array}$ & 7388 & No \\
\hline
\end{tabular}

2 


\section{Table 2 (on next page)}

Gnomonic intervals and the duration of each development stage based on the observed information for the Pacific chub mackerel (Scomber japonicus). 
1

\begin{tabular}{|c|c|c|c|c|c|c|}
\hline \multirow{2}{*}{$\begin{array}{c}\text { Gnomonic } \\
\text { interval }\end{array}$} & \multirow{2}{*}{$\begin{array}{c}\text { Development } \\
\text { stage }\end{array}$} & \multicolumn{3}{|c|}{ age (days) } & $\begin{array}{c}\text { Mean } \\
\text { length } \\
(\mathrm{mm})\end{array}$ & References* \\
\cline { 3 - 5 } & Egg & 0 & 2.3 & 2.3 & $1.05-1.14$ & Hunter and Kimbrell (1980) \\
\hline 1 & Pre-larvae & 2.3 & 6 & 3.7 & $2.0-3.7$ & Hunter and Kimbrell (1980) \\
\hline 2 & Post-larvae & 6 & 16 & 10.0 & $3.5-15.0$ & $\begin{array}{c}\text { Hwang and Lee (2005) } \\
\text { Hunter and Kimbrell (1980) }\end{array}$ \\
\hline 3 & Early juvenile & 16 & 47 & 31 & $\begin{array}{c}15-30, \\
24.6\end{array}$ & $\begin{array}{c}\text { Watanabe (1970) } \\
\text { Hwang and Lee (2005) } \\
\text { Nakayama et al. (2003) }\end{array}$ \\
\hline 4 & Juvenile & 47 & 150 & 103 & $30-70$ & $\begin{array}{c}\text { Watanabe (1970) } \\
\text { Castro and Santana (2000) }\end{array}$ \\
\hline 5 & Early adult & 150 & 400 & 250 & $90-140$ & $\begin{array}{c}\text { Yasuda and Hiyama (1957) } \\
\text { Castro and Lorenzo (1991) }\end{array}$ \\
\hline 7 & Adult & 400 & 1,063 & 663 & $140-280$ & $\begin{array}{c}\text { Torrejón-Magallanes et al. } \\
\text { (2017) }\end{array}$ \\
\hline 8 & Late adult & 1,063 & 2,920 & 1857 & $281-460$ & $\begin{array}{c}\text { Kotlyar and Abramov (1982), } \\
\text { Castro and Santana (2000) }\end{array}$ \\
\hline
\end{tabular}

$2 *$ Focus on mean length (mm) and age estimates. 


\section{Table 3(on next page)}

Fecundity estimations reported in the literature for the Pacific chub mackerel (S. japonicus). 
1

\begin{tabular}{|c|c|c|c|c|}
\hline Fecundity & Min & Max & SD & References \\
\hline 78,174 & 11,805 & 144,543 & -- & Peña, Alheit \& Nakama (1986) \\
28,978 & 7,603 & 53,921 & 1,529 & Buitrón and Perea (1998) \\
\hline
\end{tabular}

2 


\section{Table 4 (on next page)}

Results using the data from Caddy (1996) for two species with high fecundity MLF = 200,000 eggs and low fecundity MLF = 135 eggs.

The value in parenthesis with asterisk refers to a difference in the estimation with respect to the original work. 


\begin{tabular}{|c|c|c|c|}
\hline \multicolumn{4}{|l|}{$\begin{array}{l}\text { Longevity }=365 \text { days } \\
M L F=200,000 \\
G=1.645 \\
\boldsymbol{\alpha}=1.382\end{array}$} \\
\hline Gnomonic interval & $\begin{array}{c}\text { Duration } \\
\text { (year) }\end{array}$ & No. survivors & $\overline{M_{i}}\left(\right.$ year $\left.^{-1}\right)$ \\
\hline 1 & 0.005 & 38,614 & 300.16 \\
\hline 2 & 0.008 & 7,455 & 217.25 \\
\hline 3 & 0.018 & 1,439 & $91.22(* 91.27)$ \\
\hline 4 & 0.043 & 278 & 38.30 \\
\hline 5 & 0.102 & 54 & 16.08 \\
\hline 6 & 0.204 & 10 & 6.75 \\
\hline 7 & 0.580 & 2 & 2.84 \\
\hline \multicolumn{4}{|l|}{ MLF $=135$} \\
\hline \multicolumn{4}{|l|}{$\mathrm{G}=0.602$} \\
\hline \multicolumn{4}{|l|}{$\boldsymbol{\alpha}=1.382$} \\
\hline Gnomonic interval & $\begin{array}{c}\text { Duration } \\
\text { (year) }\end{array}$ & No. survivors & $\overline{M_{i}}\left(\right.$ year $\left.^{-1}\right)$ \\
\hline 1 & 0.005 & 74 & 109.82 \\
\hline 2 & 0.008 & 41 & 79.48 \\
\hline 3 & 0.018 & 22 & 33.37 \\
\hline 4 & 0.043 & 12 & 14.01 \\
\hline 5 & 0.102 & 7 & 5.88 \\
\hline 6 & 0.244 & 4 & 2.47 \\
\hline 7 & 0.580 & 2 & 1.04 \\
\hline
\end{tabular}

2

3 


\section{Table 5 (on next page)}

Estimates of natural mortality $(M)$ and durations for each gnomonic interval for the Pacific chub mackerel (Scomber japonicus) with different MLFs (assuming a uniform distribution), and egg stage durations. 
1

\begin{tabular}{|c|c|c|c|c|c|c|c|c|c|}
\hline $\begin{array}{l}\text { Longevity }=2,920 \text { day } \\
M L F=78,174[11,805 \\
G=1.30 \\
\boldsymbol{\alpha}=1.99\end{array}$ & & & & $\boldsymbol{\alpha}=1.77$ & & & $\boldsymbol{\alpha}=1.49$ & & \\
\hline Stage of development & $\begin{array}{c}\text { Duration } \\
\text { (days) }\end{array}$ & $\begin{array}{c}\overline{M_{\mathrm{i}}} \\
\left(\text { year-1) }^{-1}\right)\end{array}$ & $\sigma \mathrm{i}$ & $\begin{array}{c}\text { Duration } \\
\text { (days) }\end{array}$ & $\begin{array}{c}\overline{\mathrm{M}_{\mathrm{i}}} \\
\left(\text { year }^{-1}\right)\end{array}$ & $\sigma \mathrm{i}$ & $\begin{array}{c}\text { Duration } \\
\text { (days) }\end{array}$ & $\begin{array}{c}\overline{M_{\mathrm{i}}} \\
\left(\text { year-1) }^{-1}\right)\end{array}$ & $\sigma \mathrm{i}$ \\
\hline Egg & 1.38 & 344.44 & 0.05750 & 2.33 & 202.98 & 0.03389 & 4.88 & 97.15 & 0.01622 \\
\hline Prelarvae & 2.73 & 173.31 & 0.02893 & 4.13 & 114.67 & 0.01914 & 7.28 & 65.06 & 0.01086 \\
\hline Postlarvae & 8.16 & 58.01 & 0.00968 & 11.44 & 41.40 & 0.00691 & 18.15 & 26.09 & 0.00436 \\
\hline Early juvenile & 24.39 & 19.42 & 0.00324 & 31.69 & 14.94 & 0.00249 & 45.25 & 10.46 & 0.00175 \\
\hline Juvenile & 72.86 & 6.50 & 0.00109 & 87.79 & 5.40 & 0.00090 & 112.83 & 4.20 & 0.00070 \\
\hline Early adult & 217.66 & 2.18 & 0.00036 & 243.17 & 1.95 & 0.00033 & 281.33 & 1.68 & 0.00028 \\
\hline Adult & 650.25 & 0.73 & 0.00012 & 673.59 & 0.70 & 0.00012 & 701.43 & 0.68 & 0.00011 \\
\hline Late adult & $1,942.57$ & 0.27 & 0.00004 & $1,865.86$ & 0.25 & 0.00004 & $1,748.86$ & 0.24 & 0.00005 \\
\hline MLF $=28,978[7,603$ & & & & & & & & & \\
\hline $\mathrm{G}=1.19$ & & & & & & & & & \\
\hline $\boldsymbol{\alpha}=1.99$ & & & & $\boldsymbol{\alpha}=1.77$ & & & $\boldsymbol{\alpha}=1.49$ & & \\
\hline Stage of development & $\begin{array}{c}\text { Duration } \\
\text { (days) }\end{array}$ & $\begin{array}{c}\overline{M_{\mathrm{i}}} \\
\left(\text { year- }^{-1}\right)\end{array}$ & $\sigma \mathrm{i}$ & $\begin{array}{l}\text { Duration } \\
\text { (days) }\end{array}$ & $\begin{array}{c}\overline{M_{\mathrm{i}}} \\
\left(\text { year }^{-1}\right)\end{array}$ & $\sigma \mathrm{i}$ & $\begin{array}{c}\text { Duration } \\
\text { (days) }\end{array}$ & $\begin{array}{c}\mathrm{M}_{\mathrm{i}} \\
\left(\text { year-1-1) }^{-1}\right)\end{array}$ & $\sigma \mathrm{i}$ \\
\hline Egg & 1.38 & 315.16 & 0.04733 & 2.33 & 185.72 & 0.02789 & 4.88 & 88.89 & 0.01335 \\
\hline Prelarvae & 2.73 & 158.58 & 0.02381 & 4.13 & 104.92 & 0.01576 & 7.28 & 59.53 & 0.00894 \\
\hline Postlarvae & 8.16 & 53.08 & 0.00797 & 11.44 & 37.88 & 0.00569 & 18.15 & 23.87 & 0.00359 \\
\hline Early juvenile & 24.39 & 17.77 & 0.00267 & 31.69 & 13.67 & 0.00205 & 45.25 & 9.57 & 0.00144 \\
\hline Juvenile & 72.86 & 5.95 & 0.00089 & 87.79 & 4.93 & 0.00074 & 112.83 & 3.84 & 0.00058 \\
\hline Early adult & 217.66 & 1.99 & 0.00030 & 243.17 & 1.78 & 0.00027 & 281.33 & 1.54 & 0.00023 \\
\hline Adult & 650.25 & 0.67 & 0.00010 & 673.59 & 0.64 & 0.00010 & 701.43 & 0.62 & 0.00009 \\
\hline Late adult & $1,942.57$ & 0.25 & 0.00003 & $1,865.86$ & 0.23 & 0.00003 & $1,748.86$ & 0.22 & 0.00004 \\
\hline
\end{tabular}


Table 6(on next page)

Estimates and assumed values of natural mortality $(M)$ for the Pacific chub mackerel (Scomber japonicus) based on different methods. 


\begin{tabular}{|c|c|c|c|c|}
\hline $\begin{array}{c}\text { Stage of } \\
\text { development }\end{array}$ & $\mathrm{M}\left(\right.$ year $\left.^{-1}\right)$ & Area & Method & Reference \\
\hline Fish larvae & 51.1 & Japan & Rearing conditions & Watanabe (1970) \\
\hline Adults & $0.52-0.53$ & Peru & Pauly estimator & $\begin{array}{c}\text { Caramantin-Soriano, } \\
\text { Vega-Pérez \& Ñiquen } \\
\text { (2008) }\end{array}$ \\
\hline Adults & 0.5 & California current & Regression of $\mathrm{Z}$ on $\mathrm{F}$ & $\begin{array}{c}\text { Parrish and MacCall } \\
\text { (1978) }\end{array}$ \\
\hline Adults & 0.5 & $\begin{array}{c}\text { Eastern Central } \\
\text { Pacific }\end{array}$ & *Regression of $\mathrm{Z}$ on $\mathrm{F}$ & Patterson et al. (1993) \\
\hline Adults & 0.5 & $\begin{array}{l}\text { Southern California - } \\
\text { Northern Baja } \\
\text { California }\end{array}$ & *Regression of $\mathrm{Z}$ on $\mathrm{F}$ & MacCall et al. (1985) \\
\hline Juveniles - Adults & 1.01 & Gulf of California & Length frequency data & Cisneros et al. (1990) \\
\hline Adults & 0.5 & Japan & *Empirical equation & Yatsu et al. (2002) \\
\hline Juvenile - Adults & 0.81 & U.S.A, Mexico & Statistical catch at age & Crone et al. (2019) \\
\hline
\end{tabular}

2 *assumed value 